\title{
Biomarkers in the Lung Cancer Diagnosis: A Clinical Perspective
}

\author{
X. LI* T. ASMITANANDA, L. GAO, D. GAI, Z. SONG, Y. ZHANG, H. REN, T. YANG, T. CHEN, M. CHEN*
}

Department of Respiratory Medicine, The First Affiliated Hospital of Xian Jiaotong University, School of Medicine, Xian Jiaotong University, Xian-710061

${ }^{*}$ Correspondence: chenmingwei@mail.xjtu.edu.cn

${ }^{\ddagger}$ Contributed equally to this work.

Received December 14, 2011 / Accepted March 20, 2012

\begin{abstract}
The propensity for tumor biomarkers to be detected in serum at an early disease stage has become an area of interest for clinicians. This study aimed to evaluate the efficiency of 7 tumor biomarkers, namely, carcinoembryonic antigen (CEA), neuron-specific enolase (NSE), cytokeratin 19 (CYFRA-21-1), alpha-fetoprotein, carbohydrate antigen-125 (CA-125), carbohydrate antigen-19.9 (CA-19.9), and ferritin, independently or in combination for the diagnosis of lung cancer. Electrochemiluminescence immunization was used to determine biomarker levels expressed in 530 patients with pulmonary disease and 229 healthy subjects. The observed levels of CEA, NSE, CYFRA-21-1, CA-125, and CA-19.9 in patients with pathologically confirmed lung cancer were significantly higher than those in patients with benign pulmonary disease or control subjects. Adenocarcinoma, squamous cell carcinoma, and small cell carcinoma of the lung were associated with the highest observed levels of CA-125, CYFRA-21-1, and NSE, respectively. Combining biomarkers successfully led to the diagnosis of lung cancer. CEA + NSE + CA-125 showed the highest sensitivity for small cell carcinoma, at 83.33\%, whereas CEA + NSE + CYFRA21-1 + CA-125 showed $94.11 \%$ sensitivity for squamous cell carcinoma. The combination of 6 biomarkers, namely, CEA + NSE + CYFRA-21-1 + CA-125 + ferritin + CA-19.9, showed 80.49\% sensitivity for adenocarcinoma. Combining biomarkers significantly aided in the diagnosis of lung cancer. However, this increased sensitivity on combination was accompanied by a decreased specificity for lung cancer subtypes. Combining biomarkers appropriately increases their sensitivity and helps with the diagnosis of lung cancer.
\end{abstract}

Key words: biomarker, combination, diagnosis, lung cancer, sensitivity, specificity

According to World Health Organization data, 7.6 million cancer deaths occurred worldwide in 2008, of which 1.4 million were due to lung cancer alone, making neoplasm of the lung the leading cause of cancer deaths (1). The worsening of risk factors for the disease and aging of the population may be the major contributors to the fact that lung cancer has become one of the most common malignant neoplasms in the world (2). In the absence of a reliable screening tool, less than $15 \%$ of patients are diagnosed with early stage I lung cancer, and less than $15 \%$ of all patients survive for 5 years after the diagnosis. In developing countries, more than $80 \%$ of patients are ineligible for surgical resection at diagnosis, mostly because of the advanced stage of the cancer, but also due to a poor general condition $(3,4)$.

Characteristically, lung cancer at its initial development is radiologically occult. Screening using sputum cytology has been used with limited success (5). Evaluation using low-dose spiral computed tomography scanning as a screening tool for lung cancer is being studied, but limitations of this technique include high costs and the need for repeated scanning (6). Histologic confirmation with biopsy specimens is the mainstay of lung cancer diagnosis, but patients are reluctant to undergo biopsy unless they are presented with evidence of a high likelihood of having lung cancer. Therefore, the propensity for biomarkers to be detected in serum at an early cancer stage has become an area of interest for clinicians $(7,8)$, and lung cancer biomarkers are frequently assessed to assist in the screening and diagnosis of lung cancer.

A number of diagnostic biomarkers for lung cancer have been suggested (9), including carcinoembryonic antigen (CEA), neuron-specific enolase (NSE), cytokeratin 19 (CYFRA-21-1), alpha-fetoprotein (AFP), serum carbohydrate antigen-125 (CA-125), carbohydrate antigen-19.9 (CA-19.9), and ferritin. These biomarkers have varied sensitivities for 
different subtypes of lung cancer $(10,11)$. As all of these biomarkers can be measured using electrochemiluminescence immunization, we propose that combining these biomarkers may improve their clinical diagnostic sensitivity. In our study, we evaluated the efficiency of 7 biomarkers independently or in combination for the clinical diagnosis of lung cancer.

\section{Patients and Methods}

From June 2008 to October 2010, 530 patients who came to our hospital with a clinical presentation suggestive of lung cancer were included in our study. Demographic details, case history, and clinical and imaging results were collected. Histopathologically confirmed cases of lung cancer were further categorized into non-small cell lung cancer (NSCLC) and small cell lung cancer (SCLC) groups. The study cohort included 149 confirmed cases of lung adenocarcinoma (77 men, 72 women), 103 confirmed cases of squamous cell carcinoma of the lung ( 90 men, 13 women), and 77 confirmed cases of SCLC (60 males, 17 females). A total of 201 patients (139 men, 64 women) were diagnosed with benign lung lesions (including tuberculosis, pneumonia, lung abscess, and chronic bronchitis). We also included 229 subjects ( 129 men, 100 women) who visited the hospital for a comprehensive health check-up and were free from any pathology, as healthy controls. The study was approved by the hospital ethical committee, and written consent was obtained from each subject for their participation in the study.

Peripheral blood $(2 \mathrm{~mL})$ was collected in a vacuum tube (BD Company, USA) from subjects after an overnight fast; care was taken to avoid hemolysis and lipemia formation. Each sample was centrifuged at $3000 \mathrm{rpm}$ for $5 \mathrm{~min}\left(4^{\circ} \mathrm{C}\right)$. The serum was separated from the sample after centrifugation and kept at $4{ }^{\circ} \mathrm{C}$ until analysis. Assays were performed within 5 days of sample acquisition. Electrochemiluminescence immunization (Roche cobas e411) was used to detect and measure biomarker concentrations. CEA and CA-125 kits were purchased from Abbott Corporation, USA. All other biomarker detection kits were purchased from $\mathrm{ROCH}$ Corporation, USA.

The cutoff values for the assay kits provided by the manufacturers were accepted as the clinical cutoff values. The cutoff values for the assessed markers were as follows: CEA, $<3.4 \mathrm{ng} /$ $\mathrm{mL}$; CA-125, <35 U/mL; CA-19.9, <39 U/mL; AFP, <7.02 ng/mL; CYFRA-21-1, <3.3 ng/mL; ferritin, $<30-400 \mathrm{ng} / \mathrm{mL}$; and NSE, $<15.2 \mathrm{ug} / \mathrm{L}$. The upper limit of the normal value was accepted as the critical value. When the measured value was higher than the critical value, the biomarker test was considered to be positive (indicating the existence of a tumor).

We used "a" to denote a true positive value (lung cancer was actually present, and biomarker test results were positive), "b" to denote a false positive value (lung cancer was actually absent, but biomarker test results were positive), "c" to denote a false negative value (lung cancer was actually present, but biomarker test results were negative), and "d" to denote a true negative value (lung cancer was actually absent, and the biomarker test results were negative). The sensitivity was calculated as a/ $(\mathrm{a}+\mathrm{c}) \times 100 \%$, and specificity was calculated as $d /(b+d) \times 100 \%$. The efficiency was calculated as $[a+d]$ / $[\mathrm{a}+\mathrm{b}+\mathrm{c}+\mathrm{d}]$.

Sensitivity $=$ True positive value / [True positive value + False negative value] $\times 100 \%$

Specificity $=$ True negative value $/$ [False positive value + True negative value $] \times 100 \%$

Efficiency $=($ True positive cases + True negative cases $) /$ Total number of cases

Statistical analysis. SPSS 13.0 statistical software and MICROSOFT EXCEL were used for statistical analysis. A p value of $<0.05$ was considered statistically significant. Tumor biomarker levels were averaged using $\mathrm{X} \pm \mathrm{S}$; differences between groups were compared using the (least significant difference) LSD- $t$ test and detection rates were compared using the chi-square test. Receiver Operating Characteristic [ROC] curves were used to observe the area under the curve (AUC) and standard error.

\section{Results}

Biomarker expression in the study group. CEA, NSE, CYFRA-21-1, CA-125, and CA-19.9 showed the highest level of expression among all assessed biomarkers in the lung cancer group, with a statistically significant difference between the lung cancer group and the benign lung disease and healthy groups $(\mathrm{p}<0.05)$; there was no significant difference between the expression levels of these biomarkers between the group with benign lung disease and healthy subjects $(p>0.05)$ [Table 1].

Biomarker expression in the lung cancer subtypes. Biomarker levels of CEA, CA-125, and ferritin correlated with lung adenocarcinoma; while NSE expression correlated with SCLC; where as CYFRA-21-1 expression showed highest correlation with squamous cell lung cancer subtypes. There was marked disparity between expression levels of different biomarkers $(p<0.05)$ in the lung cancer subtypes. AFP and CA-19.9 expression levels showed no discrepancy between the different pathologic subtypes ( $\mathrm{p}>0.05$ ). CA-125, CYFRA-21-1, and NSE had the highest independent true positive expression in adenocarcinoma, squamous cell carcinoma, and SCLC, respectively [Table 2].

ROC insinuation. The AUC for CEA, NSE, CYFRA-21-1, CA-125, CA-19.9, ferritin, and AFP was $0.556 \pm 0.074,0.490$ $\pm 0.067,0.654 \pm 0.067,0.711 \pm 0.049,0.616 \pm 0.071,0.645 \pm$ 0.053 , and $0.471 \pm 0.072$, respectively. NSE and AFP had the smallest AUC, which was statistically insignificant $(p>0.05)$ [Figure 1].

Combination of biomarkers. Biomarker combinations showed varying degrees of sensitivity for the pathologic subtypes of lung cancer. CEA + NSE showed 75\% sensitivity for SCLC, whereas NSE + CYFRA-21-1 and CYFRA-21-1 


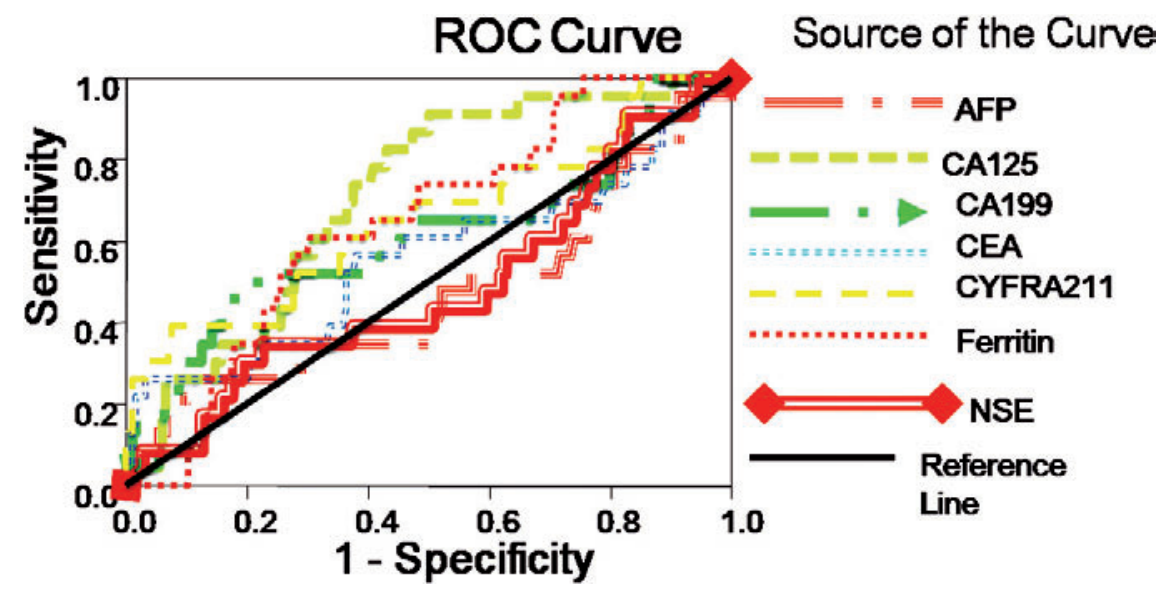

Figure 1. ROC curve for the seven biomarkers of lung cancer

+ CA-125 showed the highest sensitivity for squamous cell carcinoma (82.35\%) and lung adenocarcinoma $(73.17 \%)$, respectively. CEA + NSE + CA-125 showed $83.33 \%$ sensitivity for SCLC, but adding another biomarker did not increase this sensitivity. CEA + NSE + CYFRA-21-1 showed 88.24\% sensitivity for lung squamous cell carcinoma, which increased to $94.11 \%$ with the addition of the biomarker CA-125. A fixed sensitivity of $75.61 \%$ was seen for the combination of CEA +

Table 1. Comparison of Biomarkers Expression between the Study Groups $(\bar{X} \pm S)$

\begin{tabular}{lcccccccc}
\hline Pathological type & Total & AFP & CA-125 & CA-19.9 & CEA & CYFRA21-1 & Ferritin & NSE \\
\hline Adenocarcinoma & 149 & $2.10 \pm 1.20$ & $37.70 \pm 115.07^{\mathrm{a}}$ & $18.11 \pm 19.09^{\mathrm{a}}$ & $5.70 \pm 47.18^{\mathrm{a}}$ & $3.93 \pm 6.12^{\mathrm{ab}}$ & $295.70 \pm 302.5$ & $13.07 \pm 20.25^{\mathrm{a}}$ \\
Squamous cell & 103 & $2.20 \pm 2.61$ & $27.01 \pm 31.58^{\mathrm{ab}}$ & $10.80 \pm 25.52^{\mathrm{a}} \mathrm{b}$ & $2.87 \pm 3.85^{\mathrm{ab}}$ & $6.90 \pm 15.50^{\mathrm{a}}$ & $181.90 \pm 303.65$ & $13.35 \pm 9.32^{\mathrm{a}}$ \\
SCLC & 77 & $2.14 \pm 1.83$ & $22.37 \pm 28.91^{\mathrm{a}}$ & $10.81 \pm 28.13^{\mathrm{a}}$ & $2.71 \pm 4.13^{\mathrm{a}}$ & $2.42 \pm 3.46^{\mathrm{a}}$ & $249.50 \pm 233.85$ & $15.11 \pm 16.20^{\mathrm{ab}}$ \\
Benign lesion & 201 & $2.04 \pm 1.22$ & $21.50 \pm 48.97$ & $10.50 \pm 18.66$ & $2.34 \pm 2.27$ & $2.16 \pm 1.91$ & $168.60 \pm 409.6$ & $10.84 \pm 6.24$ \\
Healthy control & 229 & $2.03 \pm 1.44$ & $15.22 \pm 19.76$ & $10.35 \pm 10.77$ & $1.94 \pm 1.55$ & $1.99 \pm 2.01$ & $157.80 \pm 267.79$ & $10.86 \pm 5.47$ \\
P value & & 0.752 & 0.000 & 0.003 & 0.000 & 0.000 & 0.761 & 0.000 \\
\hline
\end{tabular}

Note

a - Comparison with healthy control and benign lesion group, $\mathrm{P}<0.05$.

The p-values of groups were calculated using the completely random design (CRD) of SPSS13.0. e.g.: AFP values of lung adenocarcinoma was feed into the SPSS 13.0 data software as one group, followed by AFP values of other lung cancer subtypes as individual groups, respectively. CRD was used to calculate the P-value of AFP. $\mathrm{P}<0.05$ meant statistical significance.

b - Comparison between pathological subtypes of lung cancer, $\mathrm{P}<\mathbf{0 . 0 5}$.

Difference between the groups was compared using LSD-t test in SPSS. LSD-t test results displayed "*»; when difference between two groups were statistically significant. In AFP and ferritin groups, all the P-value is above 0.05 .

P values of comparison between the study groups

\begin{tabular}{|c|c|c|c|c|c|c|c|}
\hline \multirow{2}{*}{ Comparing Groups } & \multicolumn{7}{|c|}{ Biomarker } \\
\hline & AFP & CA-125 & CA-199 & CEA & CYFRA21-1 & ferritin & NSE \\
\hline Adenocarcinoma v/s. Squamous cell & 0.948 & 0.009 & 0.011 & 0.031 & 0.013 & 0.966 & 0.778 \\
\hline Adenocarcinoma v/s SCLC & 0.973 & 0.877 & 0.636 & 0.349 & 0.000 & 0.991 & 0.040 \\
\hline Adenocarcinoma v/s Benign lesion & 0.917 & 0.000 & 0.000 & 0.000 & 0.010 & 0.313 & 0.054 \\
\hline Adenocarcinoma v/s Healthy & 0.461 & 0.000 & 0.000 & 0.000 & 0.006 & 0.654 & 0.032 \\
\hline Squamous cell v/s SCLC & 0.934 & 0.003 & 0.007 & 0.039 & 0.563 & 0.966 & 0.043 \\
\hline Squamous cell v/s Benign lesion & 0.877 & 0.020 & 0.021 & 0.047 & 0.000 & 0.385 & 0.048 \\
\hline Squamous cell v/s Healthy & 0.627 & 0.007 & 0.015 & 0.040 & 0.000 & 0.638 & 0.035 \\
\hline SCLC v/s Benign lesion & 0.974 & 0.018 & 0.000 & 0.049 & 0.020 & 0.514 & 0.000 \\
\hline SCLC v/s Healthy & 0.603 & 0.005 & 0.000 & 0.046 & 0.017 & 0.785 & 0.000 \\
\hline Benign lesion v/s Healthy & 0.209 & 0.747 & 0.995 & 0.999 & 0.766 & 0.320 & 0.935 \\
\hline
\end{tabular}


Table 2. Independent Biomarker Expression in Subtypes of Lung Cancer (\%)

\begin{tabular}{|c|c|c|c|c|c|c|c|}
\hline Pathological type & AFP & CA-125 & CA-19.9 & CEA & CYFRA21-1 & Ferritin & NSE \\
\hline Squamous cell & 9.52 & 26.09 & 18.18 & 43.00 & 69.44 & 21.81 & 38.30 \\
\hline Adenocarcinoma & 2.56 & 72.00 & 11.76 & 60.39 & 55.00 & 28.57 & 35.09 \\
\hline SCLC & 5.88 & 35.71 & 16.67 & 37.10 & 42.86 & 23.08 & 50.00 \\
\hline $\mathbf{P}$ & 0.19 & 0.00 & 0.09 & 0.00 & 0.00 & 0.03 & 0.00 \\
\hline
\end{tabular}

Table 3. Biomarker combinations and diagnosis of lung cancer

\begin{tabular}{|c|c|c|c|c|c|c|}
\hline \multirow[t]{2}{*}{ Biomarker combination } & \multicolumn{4}{|c|}{ Sensitivity (\%) } & \multirow{2}{*}{$\begin{array}{c}\text { Specificity } \\
(\%)\end{array}$} & \multirow{2}{*}{$\begin{array}{c}\text { Efficiency } \\
(\%)\end{array}$} \\
\hline & $\begin{array}{c}\text { Adenocarci- } \\
\text { noma }\end{array}$ & $\begin{array}{c}\text { Squamous } \\
\text { cell }\end{array}$ & SCLC & $\begin{array}{l}\text { Lung } \\
\text { cancer }\end{array}$ & & \\
\hline $\mathrm{CEA}+\mathrm{CA}-125$ & 68.29 & 61.76 & 58.33 & 64.37 & 51.79 & 57.29 \\
\hline $\mathrm{CEA}+\mathrm{NSE}$ & 58.54 & 70.59 & 75.00 & 65.52 & 57.14 & 60.80 \\
\hline CEA+CYFRA21-1 & 70.73 & 85.29 & 66.67 & 64.37 & 53.57 & 58.29 \\
\hline CEA+CA199 & 46.34 & 52.94 & 58.33 & 62.07 & 66.96 & 64.82 \\
\hline $\mathrm{NSE}+\mathrm{CA}-125$ & 58.54 & 55.88 & 58.33 & 54.02 & 61.61 & 63.32 \\
\hline CA-125+CYFRA21-1 & 73.17 & 73.53 & 50.00 & 54.02 & 55.36 & 54.99 \\
\hline CA-125+ CA199 & 51.22 & 23.53 & 41.67 & 50.57 & 66.96 & 57.80 \\
\hline CA199+ NSE & 39.02 & 40.06 & 58.33 & 54.02 & 76.79 & 66.83 \\
\hline CA199+ CYFRA21-1 & 51.22 & 67.65 & 50.00 & 67.82 & 72.32 & 70.35 \\
\hline NSE+CYFRA21-1 & 68.58 & 82.35 & 58.33 & 71.26 & 66.96 & 68.84 \\
\hline $\mathrm{NSE}+\mathrm{CEA}+\mathrm{CA}-125$ & 70.73 & 82.35 & 83.33 & 77.01 & 49.96 & 62.31 \\
\hline CEA+CA-125+CYFRA21-1 & 75.61 & 85.29 & 75.00 & 79.31 & 39.29 & 61.81 \\
\hline NSE+CA-125+CYFRA21-1 & 65.85 & 85.29 & 66.67 & 73.56 & 59.88 & 65.83 \\
\hline CEA+NSE+CYFRA21-1 & 75.61 & 88.24 & 75.00 & 80.46 & 47.32 & 66.83 \\
\hline NSE+CA199+ CYFRA21-1 & 58.54 & 82.35 & 58.33 & 67.82 & 51.79 & 58.80 \\
\hline CEA+CA199+ CYFRA21-1 & 70.73 & 85.29 & 66.67 & 73.56 & 46.43 & 58.29 \\
\hline $\mathrm{CEA}+\mathrm{CA} 199+\mathrm{NSE}$ & 58.54 & 70.59 & 75.00 & 65.52 & 50.89 & 59.29 \\
\hline NSE+CA-125+CA199 & 60.98 & 55.88 & 66.67 & 59.77 & 51.79 & 55.28 \\
\hline $\mathrm{CEA}+\mathrm{CA}-125+\mathrm{CA} 199$ & 68.29 & 61.76 & 75.00 & 66.67 & 46.43 & 55.28 \\
\hline CA199+CA-125+CYFRA21-1 & 68.29 & 73.53 & 58.33 & 70.11 & 48.21 & 57.79 \\
\hline $\mathrm{CEA}+\mathrm{NSE}+\mathrm{CYFRA21-1+CA-125}$ & 75.61 & 94.11 & 83.33 & 83.91 & 34.82 & 56.28 \\
\hline CA-199+NSE+CYFRA21-1+CA-125 & 68.29 & 85.29 & 66.67 & 74.71 & 44.64 & 57.79 \\
\hline $\mathrm{CEA}+\mathrm{NSE}+\mathrm{CA}-199+\mathrm{CA}-125$ & 70.73 & 82.35 & 75.00 & 73.56 & 42.86 & 56.28 \\
\hline $\mathrm{CEA}+\mathrm{NSE}+\mathrm{CYFRA} 21-1+\mathrm{CA}-199$ & 70.73 & 88.23 & 75.00 & 78.16 & 42.86 & 58.29 \\
\hline CA-125+CEA+CYFRA21-1+CA-199 & 75.61 & 91.18 & 75.00 & 81.61 & 39.29 & 57.79 \\
\hline CEA+NSE+CYFRA21-1+CA-125+CA199 & 75.61 & 94.11 & 83.33 & 83.91 & 35.71 & 56.78 \\
\hline $\mathrm{CEA}+\mathrm{NSE}+\mathrm{CYFRA} 21-1+\mathrm{CA}-125+$ Ferritin+CA-199 & 80.49 & 94.11 & 83.33 & 86.21 & 27.68 & 53.27 \\
\hline CEA+NSE+CYFRA21-1+CA-125+CA199+AFP & 75.61 & 94.11 & 83.33 & 83.91 & 34.82 & 56.28 \\
\hline CEA+NSE+CYFRA21-1+CA-125+Ferritin+CA-199+AFP & 80.49 & 94.11 & 83.33 & 86.21 & 26.79 & 52.76 \\
\hline
\end{tabular}

\section{Note:}

Sensitivity $=$ True positive cases $/$ (True positive cases + False negative cases).

Specificity $=$ True negative cases $/$ (True negative cases + False positive cases) .

Efficiency $=$ (True positive cases + True negative cases $) /$ Total number of cases.

NSE + CYFRA-21-1 and CEA + CA-125 + CYFRA-21-1 for the detection of lung adenocarcinoma. This sensitivity increased to $80.49 \%$ when combining CEA + NSE + CYFRA-21-1 + CA-125 + ferritin + CA-19.9. With an increasing number of biomarkers, the detection sensitivity increased; however, this increased sensitivity appeared to be accompanied by a decreased specificity [Table 3].

\section{Discussion}

The expression level of 7 tumor markers was measured in 759 subjects, including 329 patients with pathologically confirmed lung cancer, 201 patients with benign lung disease, and 229 healthy controls, in order to examine the sensitivity and specificity of each biomarker in the detection of lung cancer. 
Combining biomarkers increased the sensitivity for lung cancer detection and provided useful insight into the pathologic subtypes. However, larger combinations were accompanied by decreased specificity.

The presence of biomarkers in the plasma of patients with lung cancer has aroused great clinical interest, since, with a simple blood test, a valid biomarker could be used for screening, diagnosis, prognosis, progression assessment, and monitoring of therapeutic response (8). However, the lack of a uniform approach to extraction and quantification has made the standardization of any particular biomarker difficult (7). Moreover, the presence of individual free circulating biomarkers has been reported not only in patients with lung cancer, but also in patients suffering from benign lung lesions and other malignancies, and even healthy subjects (12-15). Various hypotheses have been proposed to explain these phenomena, but researchers agree on the fact that biomarker concentrations are generally higher in patients with malignant pathologies as compared to healthy controls. More intriguing is the question of whether a biomarker combination can increase the diagnostic sensitivity in lung cancer.

Originally described by Gold et al. (16), CEA expression has been reported to be higher in patients with glandular cancer (17). Earlier findings (18-20), suggested the presence of elevated CEA levels in some benign tumors and chronic conditions such as hepatic cirrhosis, colonic polyp, and smokers, we found a very high sensitivity and specificity of CEA for adenocarcinoma of the lung; a possible explanation for this observation may be our exclusion of unhealthy subjects from the control group. This finding suggests that plasma CEA levels can be used as a diagnostic marker inclusive of lung adenocarcinoma. Higher levels of AFP have previously been shown to be highly suggestive of cancer of the gastrointestinal, reproductive, and genitourinary systems. In contrast, our results did not find any significant statistical difference in the expression level of AFP and ferritin between the 3 study groups. We believe that this observation requires further evaluation.

Recent evidence (21-23) suggests the existence of a correlation between ferritin level and malignancy, with elevated serum ferritin levels observed in lymphoma, Hodgkin's disease, breast cancer, ovarian cancer, and colon cancer (24-26). Our results demonstrate a very low level of ferritin expression in the pathologic subtypes of lung cancer; a possible explanation for this discrepancy may be the variation in the inflammatory status of the associated tissues.

It has been reported (27) that serum levels of NSE are highest in tumors of neuroendocrine origin. NSE is an isoenzyme of enolase, and a large amount of clinical data (28-33) has confirmed its high sensitivity and specificity for SCLC. In our study, NSE levels were highest in SCLC, and NSE levels in SCLC were the highest amongst the 7 biomarkers assessed. However, the diagnostic accuracy of NSE appears to be low, as depicted by the fact that the lowest area under the ROC curve was observed for NSE. A likely explanation for this observa- tion may be the small number of patients with SCLC that were included in our study.

CA-19.9 is an oligosaccharide, initially reported as a glycoprotein extract from the colonic mucosa by Koprowski in 1979 (34). Recent reports suggest (35-39) that CA-19.9 is a more reliable biomarker for pancreatic carcinoma. Our study found the highest levels of CA-19.9 expression in adenocarcinoma and squamous cell carcinoma of the lung. These results suggest that CA-19.9 may be used as a diagnostic marker for NSCLC. Some studies (40-42) have reported elevated CA-19.9 levels in interstitial pneumonia; we believe that the augmented expression of CA-19.9 in benign lung disease may be the result of extensive damage to the lung parenchyma.

CA-125 is considered to be a diagnostic guide for tumors of the urinary system. Previous reports have indicated that the sensitivity and specificity of CA-125 in diagnosing ovarian cancer are $72 \%$ and $95 \%$, respectively $(43,44)$. However, the specificity of CA-125 in the diagnosis of malignant tumors remains controversial. In our study, the CA-125 detection rate was highest in the lung adenocarcinoma group, which is in agreement with earlier findings that CA-125 is expressed in about $51 \%$ of lung cancer tissues, with the expression level closely related to the degree of differentiation of the tumor.

CYFRA-21-1 is widespread in epithelial cells; the malignant transformation of epithelial cells activates protease, which accelerates the degradation of keratin, thereby resulting in the release of CYFRA-21-1 into the blood. It has been reported that CYFRA-21-1 expression is higher in patients with squamous cell carcinoma than in patients with glandular cancer and SCLC (45-51). The results of our study are consistent with earlier findings, as CYFRA-21-1 showed the highest expression level in the squamous cell carcinoma group, suggesting that CYFRA-21-1 represents an efficient biomarker for the diagnosis of squamous cell carcinoma. Early reports $(50,52)$ showed that the combination of CYFRA-21-1 and CA-125 has a high sensitivity for squamous cell carcinoma of other body regions; however, we found that the combination of CYFRA21-1 and NSE showed a high sensitivity for both the squamous cell carcinoma and adenocarcinoma subtypes of lung cancer. This discrepancy requires further evaluation.

Combining the evaluated biomarkers in the present study increased the detection rate of lung cancer. The 7-biomarker combination produced the highest detection rate, at $80.49 \%$ for adenocarcinoma, $94.11 \%$ for squamous cell carcinoma, $83.33 \%$ for SCLC, and $86.21 \%$ for lung cancer. Thus, it appears that the 7-biomarker combination can provide a high sensitivity (86.21\%) for detecting lung cancer; however, this high sensitivity was associated with compromised specificity (26.79\%). The 3-biomarker combination of CEA + NSE + CYFRA21-1 showed the highest sensitivity (75.61\%) and specificity (47.32\%) for lung adenocarcinoma, which was not increased by the addition of another biomarker; rather, a decrease in specificity was observed. These observations differed from those of Molina et al., who found that CEA + CYFRA-21-1 showed the highest sensitivity for adenocarcinoma (53). The combina- 
tion of NSE + CEA + CA-125 showed 83.33\% sensitivity for SCLC in our study, with all other combinations associated with a clear decrease in specificity. This finding suggests that the 3-biomarker combination of NSE + CEA + CA-125 may help with the diagnosis of SCLC. The 4-biomarker combination of CEA + NSE + CYFRA-21-1 + CA-125 showed the highest sensitivity (94.11\%) and specificity (83.91\%) for squamous cell carcinoma, illustrating that this combination may aid in the diagnosis of this pathologic subtype. Refinements of sampling techniques and new development in tumor biomarker combination array and nanotechnology are critically important in developing combinations for diagnosis of lung cancer.

Our study has certain limitations; first there is no arm of conservative follow up. Secondly, it is a single-center study and involves a group of physicians with a similar approach. We believe that a multi-centric study will provide a better approach for the generalization of results.

Cumulatively, our findings suggest that a single biomarker may not provide sufficient clues for the detection of lung cancer. However, considering the complexity of tumor origin and the heterogeneity of tumor antigen expression, a combination of biomarkers represents a useful means of assessing the histologic subtypes of lung cancer. The optimal specificity for each lung cancer subtype may be achieved by the appropriate combination of biomarkers.

Acknowledgements: The authors would like to express their gratitude to the medical staff at the department of pathology, the department of respiratory medicine and the medical record section for their help in obtaining the data. This study was supported by the grant from National Nature Science Foundation of China (grant number: 30973412).

\section{References}

[1] Incidence and prevalence of cancer both in Europe and in the wider world. Editorial. Eur J Cancer Care (Engl), 17: 515, 2008. http://dx.doi.org/10.1111/j.1365-2354.2008.01052.x

[2] WU J M, DU Y X. Summary of papers and research recommendations presented at the International Symposium on Lifestyle Factors and Human Lung Cancer, Guangzhou, China. Lung Cancer, 14 Suppl 1: S223-34, 1996. http://dx.doi. org/10.1016/S0169-5002(96)90225-1

[3] LIN H H, MURRAY M, COHEN T, COLIJN C, EZZATI M. Effects of smoking and solid-fuel use on COPD, lung cancer, and tuberculosis in China: a time-based, multiple risk factor, modelling study. Lancet, 372: 1473-83, 2008. http://dx.doi. org/10.1016/S0140-6736(08)61345-8

[4] HUANG GJ, MAO YS, ZHANG DC, SUN KL, HE J, et al. Current status and future directions of surgery for lung cancer in China. Chin Med J (Engl), 120: 619-21, 2007.

[5] DORIA-ROSE VP, MARCUS PM, SZABO E, TOCKMAN MS, MELAMED MR, et al. C. Randomized controlled trials of the efficacy of lung cancer screening by sputum cytology revisited: a combined mortality analysis from the Johns Hopkins Lung Project and the Memorial Sloan-Kettering
Lung Study. Cancer, 115: 5007-17, 2009. http://dx.doi. org/10.1002/cncr.24545

[6] EDEY AJ, HANSELL DM. CT lung cancer screening in the UK. Br J Radiol, 82: 529-31, 2009. http://dx.doi.org/10.1259/ bir/17503608

[7] MONTUENGA LM, PIO R. Current challenges in lung cancer early detection biomarkers. Eur J Cancer, 45 Suppl 1:377-8, 2009. http://dx.doi.org/10.1016/S0959-8049(09)70055-3

[8] SCOTT A, SALGIA R. Biomarkers in lung cancer: from early detection to novel therapeutics and decision making. Biomark Med, 2: 577-586, 2008. http://dx.doi.org/10.2217/ $\underline{17520363.2 .6 .577}$

[9] HIRSCHOWITZ EA. Biomarkers for lung cancer screening: interpretation and implications of an early negative advanced validation study. Am J Respir Crit Care Med, 179: 1-2, 2009. http://dx.doi.org/10.1164/rccm.200809-1395ED

[10] GOMEZ-ROCA C, RAYNAUD CM, PENAULT-LLORCA F, MERCIER O, COMMO F, et al. Differential expression of biomarkers in primary non-small cell lung cancer and metastatic sites. J Thorac Oncol, 4: 1212-20, 2009. http://dx.doi. org/10.1097/JTO.0b013e3181b44321

[11] SUNG HJ, CHO JY. Biomarkers for the lung cancer diagnosis and their advances in proteomics. BMB Rep, 41: 615-25, 2008. http://dx.doi.org/10.5483/BMBRep.2008.41.9.615

[12] GREENBERG AK, LEE MS. Biomarkers for lung cancer: clinical uses. Curr Opin Pulm Med, 13: 249-55, 2007. http://dx.doi. org/10.1097/MCP.0b013e32819f8f06

[13] EPSTEIN SP, CHEN D, ASBELL PA. Evaluation of biomarkers of inflammation in response to benzalkonium chloride on corneal and conjunctival epithelial cells. J Ocul Pharmacol Ther, 25: 415-24, 2009. http://dx.doi.org/10.1089/ jop. 2008.0140

[14] REINER AP, ARAGAKI AK, GRAY SL, WACTAWSKIWENDE J, CAULEY JA, et al. Inflammation and thrombosis biomarkers and incident frailty in postmenopausal women. Am J Med, 122: 947-54, 2009. http://dx.doi.org/10.1016/ j.amjmed.2009.04.016

[15] RIZVI AA. Cytokine biomarkers, endothelial inflammation, and atherosclerosis in the metabolic syndrome: emerging concepts. Am J Med Sci, 338: 310-8, 2009. http://dx.doi. org/10.1097/MAJ.0b013e3181a4158c

[16] GOLD P, SHUSTER J, FREEDMAN SO. Carcinoembryonic antigen (CEA) in clinical medicine: historical perspectives, pitfalls and projections. Cancer, 42: 1399-405, 1978. http:// dx.doi.org/10.1002/1097-0142(197809)42:3+<1399::AIDCNCR2820420803>3.0.CO;2-P

[17] JAPINK D, LEERS MP, SOSEF MN, NAP M. CEA in activated macrophages. New diagnostic possibilities for tumor markers in early colorectal cancer. Anticancer Res, 29: 3245-51, 2009.

[18] CORREA-GALLEGO C, WARSHAW AL, FERNANDEZDEL CC. Fluid CEA in IPMNs: A useful test or the flip of a coin? Am J Gastroenterol, 104: 796-7, 2009. http://dx.doi. org/10.1038/ajg.2008.158

[19] SREENARASIMHAIAH J, LARA LF, JAZRAWI SF, BARNETT CC, TANG SJ. A comparative analysis of pancreas cyst fluid CEA and histology with DNA mutational analysis in the detec- 
tion of mucin producing or malignant cysts. JOP, 10: 163-8, 2009.

[20] SAJID KM, PARVEEN R, DURRE S, CHAOUACHI K, NAEEM A, et al. Carcinoembryonic antigen (CEA) levels in hookah smokers, cigarette smokers and non-smokers. J Pak Med Assoc, 57: 595-9, 2007.

[21] SONG MK, CHUNG JS, SEOL YM, SHIN HJ, CHOI YJ, et al. Elevation of serum ferritin is associated with the outcome of patients with newly diagnosed multiple myeloma. Korean J Intern Med, 24: 368-73, 2009. http://dx.doi.org/10.3904/ kjim.2009.24.4.368

[22] LORENZI M, LORENZI B, VERNILLO R. Serum ferritin in colorectal cancer patients and its prognostic evaluation. Int J Biol Markers, 21: 235-41, 2006.

[23] SINGH KJ, SINGH SK, SURI A, VIJJAN V, GOSWAMI AK, et al. Serum ferritin in renal cell carcinoma: effect of tumor size, volume grade, and stage. Indian J Cancer, 42: 197-200, 2005.

[24] AULBERT E, STEFFENS O. [Serum ferritin-a tumor marker in malignant lymphomas?]. Onkologie, 13: 102-8, 1990. http://dx.doi.org/10.1159/000216735

[25] LI F, KISHIDA T, KOBAYASHI M. Serum iron and ferritin levels in patients with colorectal cancer in relation to the size, site, and disease stage of cancer. J Gastroenterol, 34: 195-9, 1999. http://dx.doi.org/10.1007/s005350050243

[26] AULBERT E, SCHMIDT CG. Ferritin--a tumor marker in myeloid leukemia. Cancer Detect Prev, 8: 297-302, 1985.

[27] ARIYOSHI Y, KUWABARA M. [Clinical significance of serum NSE assay as a tumor marker]. Nihon Rinsho, 48 Suppl: 1035-7, 1990

[28] SATOH H, ISHIKAWA H, KURISHIMA K, YAMASHITA Y T, OHTSUKA M, et al. Cut-off levels of NSE to differentiate SCLC from NSCLC. Oncol Rep, 9: 581-3, 2002.

[29] EBERT W, MULEY T, TRAINER C, DIENEMANN H, DRINGS P. Comparison of changes in the NSE levels with clinical assessment in the therapy monitoring of patients with SCLC. Anticancer Res, 22: 1083-9, 2002.

[30] SHIBAYAMA T, UEOKA H, NISHII K, KIURA K, TABATA $\mathrm{M}$, et al. Complementary roles of pro-gastrin-releasing peptide (ProGRP) and neuron specific enolase (NSE) in diagnosis and prognosis of small-cell lung cancer (SCLC). Lung Cancer, 32: 61-9, 2001. http://dx.doi.org/10.1016/S0169-5002(00)00205$\underline{1}$

[31] JORGENSEN LG, OSTERLIND K, GENOLLA J, GOMM SA, HERNANDEZ JR, et al. Serum neuron-specific enolase (S-NSE) and the prognosis in small-cell lung cancer (SCLC): a combined multivariable analysis on data from nine centres. Br J Cancer, 74: 463-7, 1996. http://dx.doi.org/10.1038/ bjc. 1996.383

[32] JORGENSEN LG, OSTERLIND K, HANSEN HH, COOPER EH. Serum neuron-specific enolase (S-NSE) in progressive small-cell lung cancer (SCLC). Br J Cancer, 70: 759-61, 1994. http://dx.doi.org/10.1038/bjc.1994.391

[33] JORGENSEN LG, OSTERLIND K, HANSEN HH, COOPER EH. Serum neuron specific enolase (NSE) is a determinant of response duration in small cell lung cancer (SCLC). Br J Cancer, 66: 594-8, 1992. http://dx.doi.org/10.1038/bjc.1992.320
[34] KOPROWSKI H, STEPLEWSKI Z, MITCHELL K, HERLYN M, HERLYN D, et al. Colorectal carcinoma antigens detected by hybridoma antibodies. Somatic Cell Genet, 5: 957-71, 1979. http://dx.doi.org/10.1007/BF01542654

[35] WASAN H S, SPRINGETT GM, CHODKIEWICZ C, WONG R, MAUREL J, et al. CA 19-9 as a biomarker in advanced pancreatic cancer patients randomised to gemcitabine plus axitinib or gemcitabine alone. Br J Cancer, 101: 1162-7, 2009. http://dx.doi.org/10.1038/sj.bjc.6605243

[36] VORMITTAG L, GLEISS A, SCHEITHAUER W, LANG F, LAENGLE F, et al. Limited value of CA 19-9 in predicting early treatment failure in patients with advanced pancreatic cancer. Oncology, 77: 140-6, 2009. http://dx.doi.org/10.1159/ $\underline{000229754}$

[37] KOOM W S, SEONG J, KIM YB, PYUN H O, SONG SY. CA 19-9 as a predictor for response and survival in advanced pancreatic cancer patients treated with chemoradiotherapy. Int J Radiat Oncol Biol Phys, 73: 1148-54, 2009. http://dx.doi. org/10.1016/j.ijrobp.2008.06.1483

[38] ATKINS CD. CA 19-9 and Lewis antigens in pancreatic cancer. J Clin Oncol, 27: 2572-3; author reply 2573, 2009. http://dx.doi.org/10.1200/JCO.2009.21.8198

[39] PEZZILLI R, CASADEI R, CALCULLI L, SANTINI D, MORSELLI-LABATE AM. Serum determination of CA 19-9 in diagnosing pancreatic cancer: an obituary. Dig Liver Dis, 42: 73-4. http://dx.doi.org/10.1016/j.dld.2009.04.015

[40] YAMAMOTO S, KOBAYASHI S, TANAKA M, AKIMOTO T, TAKASAKI Y. [Serum CA 19-9 levels in rheumatic diseases with interstitial pneumonia]. Nihon Rinsho Meneki Gakkai Kaishi, 19: 128-35, 1996. http://dx.doi.org/10.2177/ jsci.19.128

[41] OKINO T, YAMADORI I, OGINO T, MIKI H, HIRAKAWA E, et al. [An autopsied case of idiopathic interstitial pneumonia, showing a remarkably elevated serum level of CA 19-9]. Gan No Rinsho, 35: 69-73, 1989.

[42] BUNGO M, YAMAJI Y, FUTAMI H, SHIOTANI T, IRINO S, et al. [Case of idiopathic interstitial pneumonia with marked increase of serum CA-19-9]. Nihon Kyobu Shikkan Gakkai Zasshi, 26: 185-9, 1988.

[43] DONACH M, YU Y, ARTIOLI G, BANNA G, FENG W, et al. Combined use of biomarkers for detection of ovarian cancer in high-risk women. Tumour Biology, 31: 209-15, 2010. http://dx.doi.org/10.1007/s13277-010-0032-x

[44] KIM HS, KIM JW, CHO JY, CHUNG HH, PARK NH, et al. The role of serum CA-125 levels in early-stage epithelial ovarian cancer on preoperative CT and MRI. Eur J Surg Oncol, 35: 870-6, 2009. http://dx.doi.org/10.1016/j.ejso.2009.01.005

[45] NISMAN B, YUTKIN V, PERETZ T, SHAPIRO A, BARAK V, et al. The follow-up of patients with non-muscle-invasive bladder cancer by urine cytology, abdominal ultrasound and urine CYFRA 21-1: a pilot study. Anticancer Res, 29: 4281-5, 2009.

[46] MU X, GAO Z, YE R. [Correlation between Changes in Serum Level of CEA and CYFRA 21-1 and Objective Response of Chemotherapy.]. Zhongguo Fei Ai Za Zhi, 12: 1051-4, 2009.

[47] KOSACKA M, JANKOWSKA R. Comparison of cytokeratin 19 expression in tumor tissue and serum CYFRA 21-1 levels 
in non-small cell lung cancer. Pol Arch Med Wewn, 119: 33-7, 2009.

[48] HOLDENRIEDER S, VON PAWEL J, DANKELMANN E, DUELL T, FADER L, et al. Nucleosomes and CYFRA 21-1 indicate tumor response after one cycle of chemotherapy in recurrent non-small cell lung cancer. Lung Cancer, 63: 128-35, 2009. http://dx.doi.org/10.1016/j.lungcan.2008.05.001

[49] CHMURA A, WOJCIESZEK A, MROCHEM J, WALASZEKGRUSZKA A, DEJA R, et al. [Usefulness of the SCC, CEA, CYFRA 21.1, and CRP markers for the diagnosis and monitoring of cervical squamous cell carcinoma]. Ginekol Pol, 80: 361-6, 2009.

[50] AL-SHAGAHIN H, ALKOTYFAN K, MULLER HH, SESTERHENN AM, and WERNER JA. Cyfra 21-1 as a serum tumor marker for follow-up of patients with laryngeal and hypopharyngeal squamous cell carcinoma. Anticancer Res, 29: 3421-5, 2009.
[51] CHEN F, LUO X, ZHANG J, LU Y, LUO R. Elevated serum levels of TPS and CYFRA 21-1 predict poor prognosis in advanced non-small-cell lung cancer patients treated with gefitinib. Med Oncol, 27: 950-7. http://dx.doi.org/10.1007/ s12032-009-9315-8

[52] DABROWSKA M, GRUBEK-JAWORSKA H, DOMAGALAKULAWIK J, BARTOSZEWICZ Z, KONDRACKA A, et al. [Diagnostic usefulness of selected tumor markers (CA125, CEA, CYFRA 21-1) in bronchoalveolar lavage fluid in patients with non-small cell lung cancer]. Pol Arch Med Wewn, 111: 659-65, 2004.

[53] MOLINA R, FILELLA X, AUGE J M, FUENTES R, BOVER I, et al. Tumor markers (CEA, CA 125, CYFRA 21-1, SCC and NSE) in patients with non-small cell lung cancer as an aid in histological diagnosis and prognosis. Comparison with the main clinical and pathological prognostic factors. Tumour Biol, 24: 209-18, 2003. http://dx.doi.org/10.1159/000074432 